\title{
Quantitative Analysis of Cigarette Smoke Condensate Monophenols by Reverse-Phase High-Performance Liquid Chromatography*
}

\author{
by \\ G. Jeanty, J. Massé and P. Berçot \\ Laboratoire de Synthese Organique Appliquée, Faculté des Sciences Exactes et Naturelles, \\ Université de Perpignan, France \\ and \\ F. Coq \\ Division de Recherche, Societe JOB, Perpignan, France
}

\section{SUMMARY}

A rapid and quantitative method for the determination of cigarette smoke condensate monophenols using high-performance liquid chromatography (HPLC) was developed. Total particulate matter was collected on cigarette filter tips and Cambridge filter pads. Phenolic compounds were extracted with a $1 \mathrm{~N}$ sodium hydroxide solution.

Five different brands of filter-tipped cigarettes from the French market were analysed. Their phenol, guaiacol, methylphenols and dimethylphenols levels were determined in comparison with an internal standard, $\alpha$ chlorophenol.

With the same method we compared the phenolic retention efficiency of different cigarette filter tips.

\section{ZUSAMMENFASSUNG}

Es wird ein Verfahren beschrieben, das die schnelle und quantitative Bestimmung von Monophenolen im Kondensat von Zigarettenrauch mittels Hochleistungsflüssigkeitschromatographie (HPLC) ermöglicht. Die Gesamtpartikelphase wird im Zigarettenfilter und in Cambridge-Filtern aufgefangen. Die phenolischen Ver-

\footnotetext{
\# Received: 30h January 1984 - accepted: 1st August 1984.
}

bindungen werden mit einer $1 \mathrm{~N}$ Natriumhydroxidlōsung extrahiert.

Fünf verschiedene franzōsische Filterzigarettensorten wurden untersucht. Der Gehait an Phenol, Guajakol, an Methylphenolen und Dimethylphenolen wurde unter Verwendung eines inneren Standards (oChlorphenol) bestimmt.

Unter Einatz derselben Methode wurde das Filtrationsvermögen verschiedener Zigarettenfilter gegenüber den genannten Phenolen miteinander verglichen.

\section{RESUME}

Nous proposons une méthode rapide et quantitative par chromatographie liquide à haute performance (HPLC), pour analyser les monophénols du condensat de la fumée de cigarette. La phase particulaire de la fumée est piégée sur bout-filtre de cigarette et sur filtre Cambridge. Les composés phénoliques sont extraits par une solution de soude $1 \mathrm{~N}$.

Pour cinq types de cigarettes du marché français, les quantités de phénol, gaïacol, méthylphénols et diméthylphénols sont déterminées par rapport à l'ochlorophénol selon la méthode de l'étalonnage interne.

Par la même méthode, nous avons comparé l'efficacité de rétention vis-à-vis de ces phénols de différents filtres de cigarette. 


\section{INTRODUCTION}

Numerous quantitative methods have been published for determining phenolic compounds in cigarette smoke (1-8). Several leaf constituents (cellulose, lignin, polyphenolic pigments) were identified as pyrolytic precursors of smoke phenolic compounds (9-13).

Colorimetric methods involving the reactions between phenols and aryldiazonium salt or 4-aminophenazone give only an overall value of smoke phenols. Generally, this value underestimates the actual amount of smoke phenols. Chromatographic methods allow the selective and rapid analysis of the most abundant monophenols from tobacco smoke (1, 2, 4-9). Gas chromatography has been widely used. To our knowledge, only Kuwata et al. $(14,15)$ have used high-performance liquid chromatography (HPLC) to analyse tobacco smoke monophenols as azo dyes.

We propose an analytical method for determining the monophenols present in tobacco smoke condensate. Reverse-phase high-performance liquid chromatography is used for this method, without derivatization.

\section{EXPERIMENTAL}

\section{Apparatus and Reagents}

a) Liquid chromatographic separations were performed on a Waters Associates liquid chromatograph with Model 6000 A pumps. The detector was a Schoeffel M 450 variable-wavelength UV detector. Samples were injected via a Model U6K injection system.

b) A. $250 \mathrm{~mm} \times 4 \mathrm{~mm}$ inside diameter LiChrosorb RP$18(7 \mu \mathrm{m})$ (Merck) column was used at room temperature.

c) Solvents and chemical compounds were analytical grade. Phenol standards were obtained from commercially available sources. Purity was greater than $98 \%$ except for 2,4-dimethylphenol which was a mixture of $85 \%$ 2,4-dimethylphenol and $8 \% 2,5-$ dimethylphenol; it was used without further purification.

d) Cigarettes, from homogeneous batches, were smoked on a commercial Model 301 Filtrona smoking machine according to French standard NF V 37001 using Cambridge filter pads. The Cambridge and cigarette filters were subsequently collected for analytical procedures.

\section{Analytical Procedures}

First we determined the best separation conditions for reverse-phase chromatography of the major monophenols from tobacco smoke: phenol, guaiacol, methylphenols, dimethylphenols. The eluting solvents studied were: water/methanol, water/acetonitrile and water/
Figure 1.

Separation of monophenolic compounds on a LiChrosorb RP-18 column. Column: LiChrosorb RP-18 (7 $\mu \mathrm{m} ; 25 \mathrm{~cm} \times$ $4 \mathrm{~mm}$ inside diameter); mobile phase: water / acetonitrile / acetic acid $(700 / 300 / 5(\mathrm{v} / \mathrm{v}))$; flow rate: $1.0 \mathrm{ml} / \mathrm{min}$ at room temperature; UV detector: $275 \mathrm{~nm}$ wavelength).

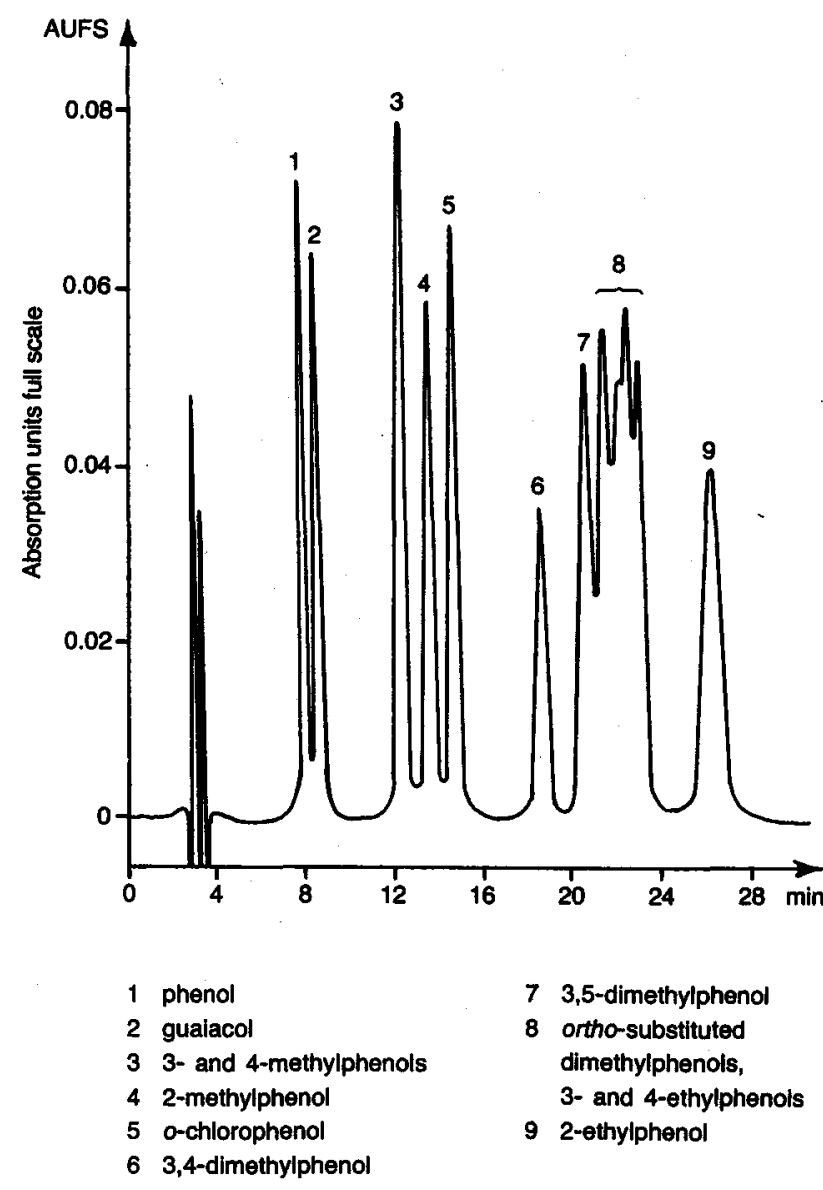

acetonitrile / acetic acid in different ratios. Comparison of the capacity factor $\left(k^{\prime}=\left(V_{R}-V m\right) / V m\right)$ and resolution $\left(R_{s}=2 \Delta V_{R} /\left(W_{1}+W_{2}\right)\right)$ between chromatograms shows that we obtain a good separation with an eluting solvent which has the following ratio: 700-300-5 (v/v) water / acetonitrile / acetic acid, and $1 \mathrm{ml} / \mathrm{min}$ as flow rate (Fig. 1). The ultraviolet absorbance detector was adjusted to $275 \mathrm{~nm}$. It is the maximum absorbance mean of the various phenols analysed.

With this procedure and an 0.01 AUFs (absorption units full scale) sensitivity, the minimum detectable amounts were: $10 \mathrm{ng}$ of phenol, $15 \mathrm{ng}$ of methylphenols, $100 \mathrm{ng}$ of 3,4-dimethylphenol. The relationship between the injected amount of each phenol and the corresponding peak height was linear at 0.1 Aurs sensitivity. Graphs for each analysed phenol were plotted at this detection sensitivity. Calibration curves were calculated by the internal standard method with o-chlorophenol as internal standard $(4,6)$. The results are shown in Table 1 and Figure 2. Figure 3 shows a chromatogram from a real sample. 
Table 1.

Linear equation parameters.

$$
q_{x}=m q_{\bullet} \frac{h_{x}}{h_{0}}+b
$$

$q_{0}$ : amount of internal standard

$h_{\mathrm{a}}$ : peak height measurement of internal standard

$q_{x}$ : amount of phenol analysed

$h_{x}$ : peak height measurement of phenol analysed

$\mathrm{m}$ : slope of the line

b : y intercept

\begin{tabular}{lcccc}
\cline { 2 - 4 } & $\mathrm{m}$ & $\mathrm{b}$ & $\mathrm{r}$ \\
\hline phenol & 0.547 & -17.0 & 0.999 \\
gualacol & 0.564 & +8.3 & 0.991 \\
3-methylphenol & 0.922 & -3.6 & 0.998 \\
4-methylphenol & 0.926 & -3.0 & 0.999 \\
2-methylphenol & 0.874 & -3.8 & 0.997 \\
3,4-dimethylphenol & 1.506 & -3.8 & 0.999 \\
\hline
\end{tabular}

correlation coefficient $r=m \frac{\sigma\left(q_{e} h_{x} / h_{e}\right)}{\sigma q_{x}}$

Figure 3.

HPLC chromatograme of clgarette smoke condensate monophenols (clgarette E). HPLC conditions and peak identity are identical with Figure 1 conditions.

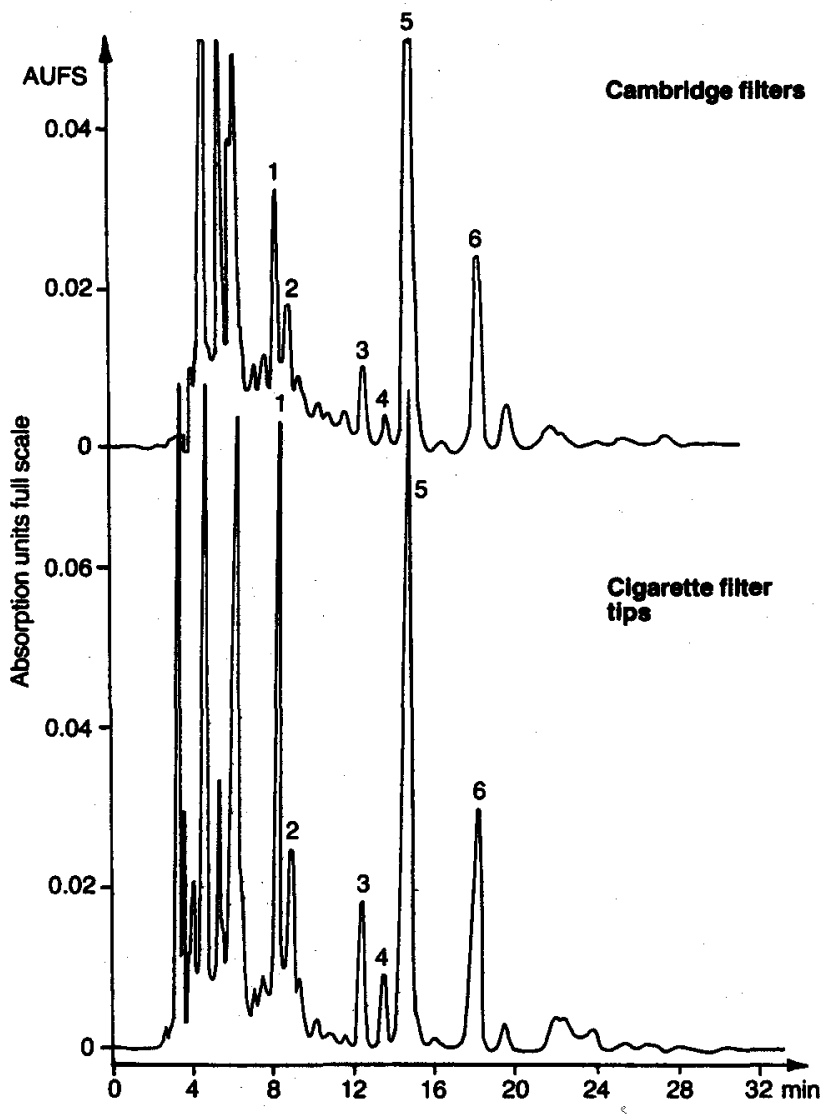

Figure 2.

Calibration curves for phenols.

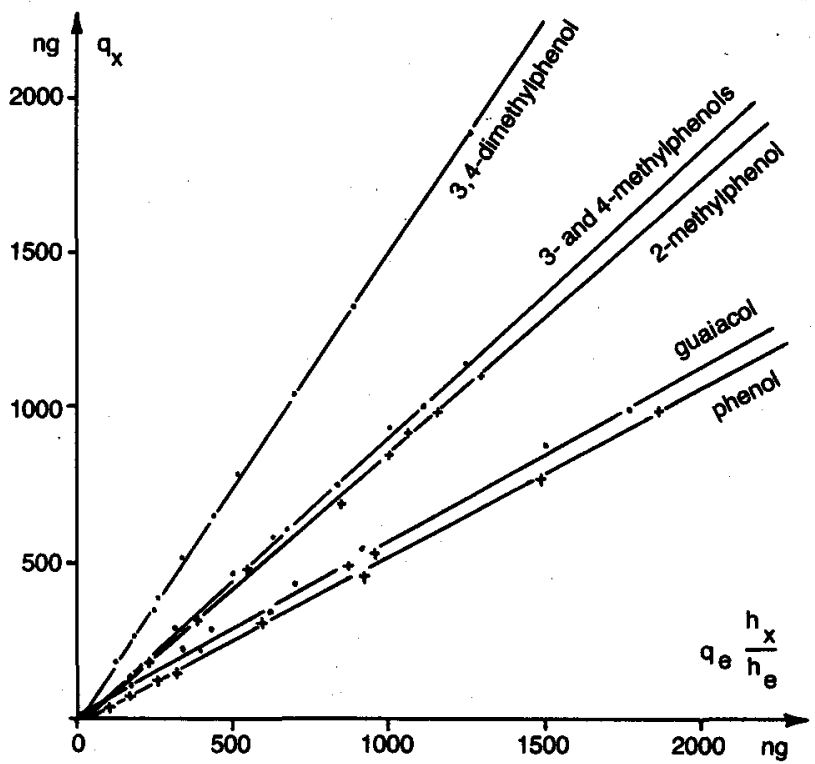

Sample Preparation

Cigarettes, selected by weight and draw resistance, were smoked through a Cambridge filter on an eightchannel smoking machine. Five cigarettes were smoked successively on each channel. The resulting total particulate matter was collected on the cigarette filter tips and on the Cambridge filter. A sample batch comprised two Cambridge filters or ten of the corresponding cigarette filter tips.

Each batch was extracted with $50 \mathrm{ml}$ of $1 \mathrm{~N}$ sodium hydroxide for two hours with intermittent stirring. The solution was filtered through a sintered glass funnel (No. 3) and then poured into a $100 \mathrm{ml}$ calibrated flask. The residue and the flask were washed with $4 \times 10 \mathrm{ml}$ portions of $1 \mathrm{~N} \mathrm{NaOH}$, then all basic extracts were combined and diluted to a final volume of $100 \mathrm{ml}$. A $20 \mathrm{ml}$ aliquot was transferred to a separatory funnel where the basic and neutral compounds were extracted from the alkaline solution with $n$-hexane $(3 \times 2 \mathrm{ml})$.

Phenols were regenerated from their salt by acidification $\left(6 \mathrm{~N} \mathrm{H}_{2} \mathrm{SO}_{4}\right)$ and extracted into ether $(5 \times 5 \mathrm{ml})$. The ether fraction was extracted with saturated sodium hydrogen carbonate solution to eliminate organic acids. It was then concentrated to approximately $1 \mathrm{ml}$ at $45^{\circ} \mathrm{C}$ in a water bath at atmospheric pressure. HPLC eluting solvent $(2 \mathrm{ml})$ was added and the residual ether was evaporated at room temperature and $100 \mathrm{~mm} \mathrm{Hg}$ pressure. The phenolic fraction was poured into a $5 \mathrm{ml}$ volumetric flask. Internal standard was added and the solution diluted to $5.0 \mathrm{ml}$ with the eluting solvent. The various extractions were quantitative for monophenols. This fact was confirmed by HPLC analysis. We did not observe the presence of studied phenols in the final extractions or residual ether. 


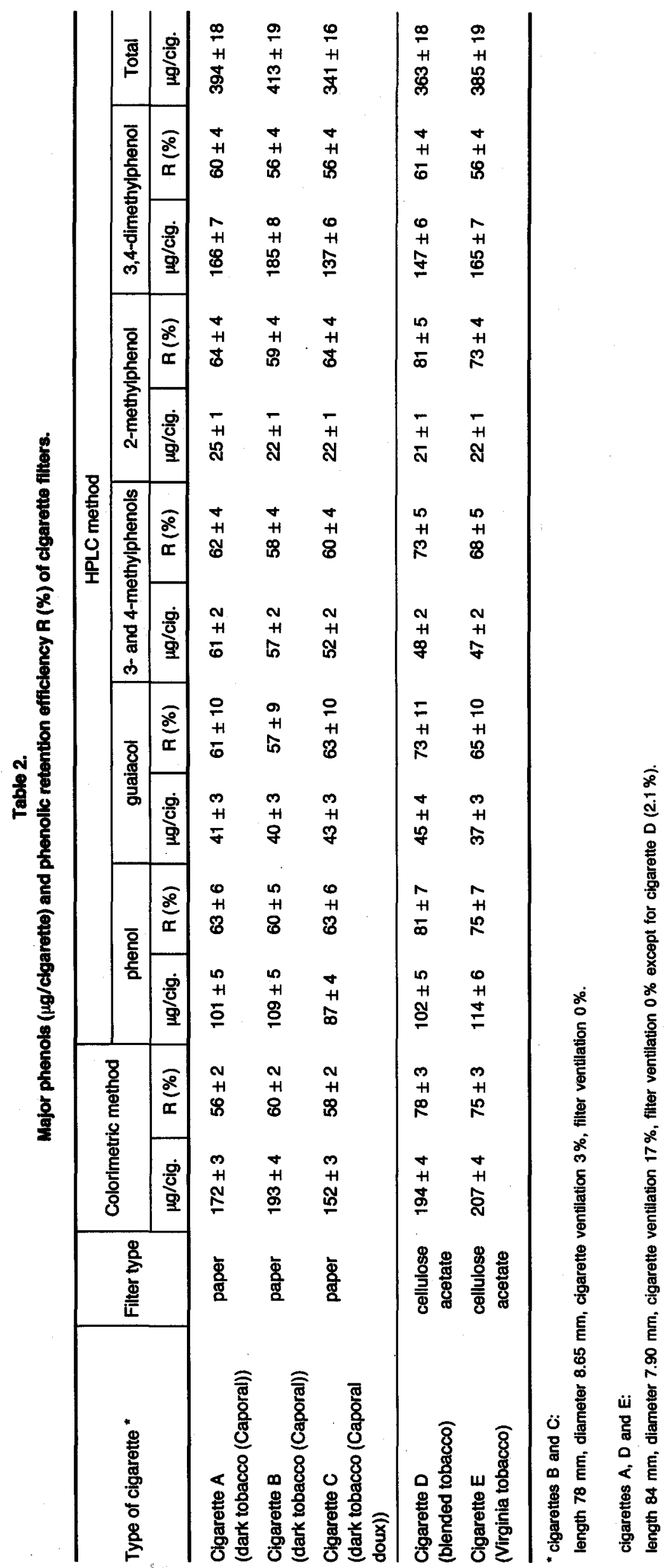


Table 3.

Retention efficiency $\mathbf{R}(\%)$ of various clgarette filters. *

\begin{tabular}{|c|c|c|c|c|c|c|c|c|c|c|}
\hline \multirow[b]{3}{*}{ Filter } & \multicolumn{2}{|c|}{ Phenol } & \multicolumn{2}{|c|}{ Guaiacol } & \multicolumn{2}{|c|}{ 3- and 4-Methylphenols } & \multicolumn{2}{|c|}{ 2-Methylphenol } & \multicolumn{2}{|c|}{ 3,4-Dimethylphenol } \\
\hline & \multicolumn{2}{|c|}{ type of cigarette } & \multicolumn{2}{|c|}{ type of cigarette } & \multicolumn{2}{|c|}{ type of cigarette } & \multicolumn{2}{|c|}{ type of cigarette } & \multicolumn{2}{|c|}{ type of cigarette } \\
\hline & $\begin{array}{c}\text { dark } \\
\text { tobacco } \\
\text { (Caporal) }\end{array}$ & $\begin{array}{l}\text { blended } \\
\text { tobacco }\end{array}$ & $\begin{array}{c}\text { dark } \\
\text { tobacco } \\
\text { (Caporal) }\end{array}$ & $\begin{array}{l}\text { blended } \\
\text { tobacco }\end{array}$ & $\begin{array}{c}\text { dark } \\
\text { tobacco } \\
\text { (Caporal) }\end{array}$ & $\begin{array}{l}\text { blended } \\
\text { tobacco }\end{array}$ & $\begin{array}{c}\text { dark } \\
\text { tobacco } \\
\text { (Caporal) }\end{array}$ & $\begin{array}{l}\text { blended } \\
\text { tobacco }\end{array}$ & $\begin{array}{c}\text { dark } \\
\text { tobacco } \\
\text { (Caporal) }\end{array}$ & $\begin{array}{l}\text { blended } \\
\text { tobacco }\end{array}$ \\
\hline Paper & $64 \pm 6$ & & $62 \pm 10$ & & $62 \pm 4$ & & $62 \pm 4$ & & $60 \pm 4$ & \\
\hline F.P. A. ** & $70 \pm 6$ & $74 \pm 6$ & $63 \pm 10$ & $67 \pm 10$ & $64 \pm 4$ & $69 \pm 4$ & $64 \pm 4$ & $71 \pm 5$ & $57 \pm 4$ & $62 \pm 4$ \\
\hline S.P. A. *** & $72 \pm 6$ & $76 \pm 6$ & $69 \pm 11$ & $74 \pm 11$ & $68 \pm 4$ & $71 \pm 5$ & $71 \pm 5$ & $77 \pm 5$ & $58 \pm 4$ & $62 \pm 4$ \\
\hline $\begin{array}{l}\text { Cellulose } \\
\text { acetate }\end{array}$ & $81 \pm 7$ & $81 \pm 7$ & $68 \pm 11$ & $74 \pm 11$ & $75 \pm 5$ & $74 \pm 5$ & $78 \pm 5$ & $81 \pm 5$ & $61 \pm 4$ & $61 \pm 4$ \\
\hline
\end{tabular}

"All of the filter cigarettes were $84 \mathrm{~mm}$ long, $7.90 \mathrm{~mm}$ in diameter and with $17 \%$ ciga-

rette ventilation and $0 \%$ filter ventilation.

** Cellulose and cellulose acetate fibre blend without definite structure.

-* Paper filter with cellulose acetate fibres. The paper is formed to $S$ structure.

\section{RESULTS AND DISCUSSION}

Five different brands of filter-tipped cigarettes from the French market were analysed by this method and compared by colorimetric determination of the total steam-volatile phenols. The results are given in Table 2. No considerable variation was observed from cigarette to cigarette in the amounts of the corresponding individual phenols. The pattern of phenol distribution was generally the same for all cigarettes studied.

Resolution of ortho-substituted dimethylphenols was insufficient but they were present at low levels. We did not observe the presence of 3,5-dimethylphenol. 3,4Dimethylphenol was present as often noted in cigarette smoke but its level was unusually high $(5-8,16)$. The difference between colorimetric and chromatographic results is explained by the fact that para-substituted phenols do not react with 4-aminophenazone (3).

Using the same method we have compared the efficiency of different filters in relation to phenolic retention. These results are given in Table 3 . We observed that the efficiency of removal of the phenolic fraction increases with the presence of cellulose acetate. The retention by cellulose acetate filters differed for individual phenols, in contrast to paper filters, with which there was no selectivity.

\section{CONCLUSION}

This paper shows that high-performance liquid chromatography is a good analytical tool for the determination of monophenols in cigarette smoke condensate.

In comparison with colorimetric or gas chromatographic methods it is simple, rapid and selective. Steam distillation and derivatization to azo dyes or volatile compounds are not necessary.

Individual monophenols are identified by their reten- tion times or elution volumes with a low detection limit. This method shows good reproducibility and its automation is possible at least for chromatographic measurement.

\section{REFERENCES}

1. Crouse, R. H., J. W. Garner and H. J. O'Neill: Determination of phenolic constituents of cigarette smoke by gas chromatography; J. Gas Chromatogr. 1 (1963) 18-22.

2. Spears, A. W.: Quantitative determination of phenol in cigarette smoke; Anal. Chem. 35 (1963) 320322.

3. Smith, G. A. L., and D. A. King: Determination of the steam-volatile phenols present in cigarettesmoke condensate, Part. I: Colorimetric determination of the total steam-volatile phenols; Analyst 89 (1964) 305-311.

4. Benner, J. F., H. R. Burton and D. Burdick: Composition of cigarette smoke from high- and lownitrate Burley tobacco; Tob. Sci. 12 (1968) 37-40.

5. Malaterre, M., J. Loheac, N. Sellier and G. Guiochon: Analyse de la fraction monophénolique des condensats de fumée de cigarettes par association de méthodes chromatographiques; Chromatographia 8 (1975) 624-628.

6. Allen, R. E., and D. G. Vickroy: The characterization of cigarette smoke from Cytrel smoking products and its comparison to smoke from flue-cured tobacco, III. Particulate phase analysis; Beitr. Tabakforsch. 8 (1976) 430-437.

7. Snook, M. E., P. J. Fortson and O. T. Chortyk: Application of gel chromatography to characterize more completely the phenols of cigarette smoke; Tob. Sci. 24 (1980) 30-36. 
8. Arrendale, R. F., R. F. Severson, O. T. Chortyk and M. E. Snook: Analyses of mono- and dihydroxybenzenes in tobacco smoke and pyrolyzates by glass capillary gas chromatography; J. of Chromatogr. Sci. 20 (1982) 136-143.

9. Benner, J. F., H. R. Burton and D. Burdick: Temperature-yield profiles of tobacco and tobacco constituents; Beitr. Tabakforsch. 5 (1969) 134-139.

10. Patterson, J. M., N. F. Haidar, S. P. Chen and W. T, Smith: An investigation of some factors affecting phenol production in tobacco pyrolyses; Tob. Sci. 20 (1976) 108-110.

11. Schlotzhauer, W. S., O. T. Chortyk and R. F. Severson: Rapid pyrolytic method for evaluating effect of tobacco variety, growing, harvesting and post-harvest treatment on smoke composition; Tob. Sci. 23 (1979) 103-106.

12. Schlotzhauer, W. S., and O. T. Chortyk: Pyrolytic studies on the origin of phenolic compounds in tobacco smoke; Tob. Sci. 25 (1981) 6-10.

13. Schlotzhauer, W. S., R. M. Martin, M. E. Snook and R. E. Williamson: Pyrolytic studies on the contribution of tobacco leaf constituents to the formation of smoke catechols; J. Agric. Food Chem. 30 (1982) $372-374$.
14. Kuwata, K, M. Uebori and Y. Yamazaki: Determination of phenol in polluted air as p-nitrobenzeneazophenol derivative by RP-HPLC; Anal. Chem. 52 (1980) 857-860.

15. Kuwata, K., M. Uebori and Y. Yamazaki: Reversedphase liquid chromatographic determination of phenols in auto exhaust and tobacco smoke as p-nitrobenzeneazophenol derivatives; Anal. Chem. 53 (1981) 1531-1534.

16. Stedman, R. L.: The chemical composition of tobacco and tobacco smoke; Chem. Rev. 68 (1968) 153-207.

Authors'address:

Laboratoire de Synthèse Organique Appliquée, Faculté des Sciences Exactes et Naturelles, Université de Perpignan,

Avenue de Villeneuve, F-66025 Perpignan, France. 